\title{
浅析高中新生怎么学好高中数学
}

平佳禾

河北省安国中学

DOI:10.32629/er.v1i3.1504

[摘 要] 数学是最能体现一个人的思维能力, 判断能力、反应敏捷能力和聪明程度的学科。数学直接影响国民的基本素质和 生活质量,良好的数学修养将人的医生可持续发展奠定基础。

[关键词] 高中数学; 学习方法; 主动学习

初高中数学知识之间有一道看不见的 “鸿沟”, 大多数 同学在初中学习数学时如鱼得水, 运用自如, 一旦步入高中, 由于不适应高中紧张的学习生活, 不适应高中数学内容抽象, 而变得萎靡不振, 少数同学甚至在困难面前失去了继续学习 数学的信心, 就像一架在初中还在正常行驶的飞机进入高中 之后突然失去了定位, 找不到方向。如何帮助同学学好高中 数学, 给同学搭一个坡度较缓的 “引桥”, 平缓地引他们走上 高中数学这架高架桥, 使同学尽快适应高中数学学习, 这需 要我们在学习过程中不断地摸索、总结。下面就这一问题谈 谈我个人的体会。

\section{1 加强入学教育,提高对高中数学的认识}

入学教育是提高同学对高中数学认识的最佳良机。利用 入学教育让同学了解高中数学学习的特点。可以采取与初中 学习对比的方法, 结合具体实例, 给同学讲清高中数学内容 体系特点和课堂教学特点, 讲二、培养对数学的学习兴趣和 良好的学习习惯。孔老夫子说, “知之者不如好之者, 好之者 不如乐之者。” “乐学” 是一种最高级的学习热情, 只有进入 到 “乐学” 这一层次, 才能使人做到在学习上自强不息。该 如何培养同学达到学习数学的 “乐学” 层次呢? 只有让同学 发现数学是好玩的, 是美的, 是和我们的日常生活息息相关 的, 那么同学就会有浓厚的兴趣。在教学过程中, 我们常看到, 学得懂、学得好的同学往往越学越觉得有趣, 而那些付出努 力可是成绩总不能提高的同学会觉得越学越累, 提不起兴趣, 甚而选择放弃。这是因为明白、懂得是兴趣产生的起点, 而 同学对自己的努力是否得到肯定以及是否受到关注, 则是学 习兴趣产生的催化剂。对同学个体自身学习情况的纵向发展 的关注, 是培养兴趣、影响学习不可忽视的重要一环。诚然, 以往从教师的角度入手, 通过提高教师的教学技能, 增强敬 业精神, 展现个人魅力等方式可以让老师的课上的精彩, 通 过幽默的教学语言, 形象生动的生活举例, 知识理论的深入 浅出等来激发同学的学习兴趣, 的确有较大的促进作用。但 不管怎么说, 这些做法都是从调整客观因素进行影响。针对 高中数学, 其科学理论性和抽象性比初中明显增强, 客观因 素的影响力愈显得相对的有限。因此, 调动同学主观因素的 积极能动性, 才是提高兴趣、提高成绩更有成效的方法。也 就是说, 我们要创设条件、创设情境以激发同学的自主学习,
要通过一些教学活动促进数学教学, 增强学习的竞争意识和 荣誉意识, 要通过相关的建模活动突出数学的基础学科优势 意识, 只有让同学了解到数学的广泛应用和不可替代的地位, 才能使同学下定决心, 排除万难地学好数学。

良好的学习习惯是学好高中数学的重要因素, 它包括制 定计划、课前预习、课后复习、专心上课、勤于思考、独立 作业、解决疑难、系统小结和课外学习这几个方面。培养良 好的学习习惯, 应引导同学养成认真制定计划的习惯, 合理 安排时间, 从盲目的学习中解放出来, 引导同学养成课前预 习的习惯, 可布置一些思考题培养他们勤于思考的习惯。课 堂提问有意设计一些散见于教材的习惯, 以强化对基本概念 的理解, 增强对知识体系的理解和记忆。

\section{2 学会赏识教育和尊重个体差异}

陶行知先生说过: 你的教鞭下、冷眼里有科学家。不要 等到坐火轮、点油灯、学微积分, 才认识他们是你当年的同 学。每个同学都有自己的优势智力领域, 有自己的学习类型 和方法。每一个同学都是自己的好朋友, 我们的眼里不应有 差生, 只有有待进步的同学, 有潜力的同学。在课堂上, 经常 鼓励、赏识同学们的表现。在赏识教育的同时, 还应考虑到 同学之间的个体差异, 要因材施教, 发掘出每个同学的学习 潜能, 尽量做到基础分流, 弹性管理。承认同学的差异, 甚至 欣赏差异, 允许失败, 哪怕同学一千次跌倒, 也坚信同学第一 千零一次会站起来。在教学中尽量采用分类教学, 分层指导 的方法, 使每一位同学都能够稳步地前进, 调动他们的学习 积极性。对于问题不要急于告诉同学答案, 而是让他们在交 流中掌握知识, 在讨论中提高能力。尽量让同学发现问题, 质疑问题, 标新立异。

\section{3 注意知识的同化和更新}

同化是把新学习的数学概念和数学规律整合到原有认 知结构的模式之中, 认知结构得到丰富和扩展, 但总的模式 不发生根本的变化。认知结构的更新是新学习的数学概念和 规律已不能为原有认知结构的模式所容纳, 需要改变原有模 式或另建新模式。初高中数学有很多衔接知识点, 如函数概 念、平面几何与立体几何相关知识等, 到高中, 它们有的加深 了,有的研究范围扩大了, 有些在初中成立的结论到高中可 能不成立了。因此, 在讲授新知识时, 我们应有意引导同学联 


\title{
基于生源多样化背景下高职学生管理改革途径分析
}

\author{
黄吉萍 \\ 广西培贤国际职业学院 \\ DOI:10.32629/er.v1i3.1513
}

[摘 要] 高等职业教育, 简称 “高职”, 是中国高等教育的重要组成部分。在教育行业快速发展的背景下,各个高职院校所接收 的学生不在局限于本地, 而是涵盖了五湖四海、世界各地,对高职院校学生管理工作提出了巨大挑战。基于此, 本文就对生源多 样化背景下高职学生管理的改革途径展开探讨, 以期为高职院校学生管理工作提供参考依据。

[关键词] 生源多样化; 高职院校; 学生管理; 改革途径

高职院校学生管理工作非常重要, 直接影响到高职院校 后续发展。在素质教育背景下, 对高职院校学生管理提出了 诸多要求, 使得以往的学生管理方法已经不再适用, 呈现出 诸多问题, 如, 学生主体性失落、学生管理方法单一等等, 难 以实现最初目标。基于此, 本文就对高职院校学生管理中存 在的问题进行分析, 并提出生源多样化背景下高职学生管理 改革途径, 力求提高学生管理工作质量。

\section{1 生源多样化背景下高职学生管理存在的问题分析}

高职院校生源不同于本科高等院校, 两者之间存在较大 差距, 如, 学生基础知识水平、教学层次、教学目标等等。高 职院校学生的学习基础差、认知能力不足, 且学习意识欠缺, 在此种情况下, 对学生管理工作造成一定难度, 使得学生管 理工作中频繁出现问题, 其中体现为以下几点:

一是, 生源多样化背景下高职学生管理存在体制问题。 高职院校在教学过程中重点培养学生技术, 所以其学生管 理工作是在教学实践的基础上展开的, 在此种情况下, 就会 造成学生管理工作中出现体制不合理的问题, 具体主要体 现在以下几个方面: 第一, 高职院校在发展过程中将主要精 力全部集中在如何招收更多的学生和如何提高学生就业率 上, 而忽视学生管理工作方法, 导致学生管理工作内容不全 面, 无法做到针对性、专业性。第二, 高职院校在展开学生 管理工作时, 存在各个部门之间工作协调不到位的问题, 如, 管理职责划分不清晰、管理标准不明确等等, 导致学生管理 工作质量难以提升。第三, 高职院校在展开学生管理工作时, 缺少具体的规章制度, 在此种情况下, 使得教学工作和管理 工作之间的关系无法得到细致协调, 从而出现学生管理工
作执行能力差等一系列问题, 对高职院校发展产生一定的 负面影响。

二是, 生源多样化背景下高职学生管理存在管理方式问 题。创新是一个国家发展的基石, 也是高职院校发展的基础, 但是受到传统教育观念的影响, 高职院校在生源多样化背景 下, 还缺少学生管理方式的创新工作, 导致学生创新实践能 力无法得到提升, 学生实际情况无法及时了解。事实上,生源 多样化背景下导致高职学生管理工作出现管理方式问题的 主要原因有以下两点: 一方面, 教师与学生之间缺少沟通交 流, 在对学生进行管理时, 所采用的管理方法不合理, 且缺少 现代化技术手段的应用, 难以提高学生管理效率。另一方面, 高职学生管理工作的管理方式单一, 如果高职院校严格执行, 就会激化学生和学校之间的矛盾, 从而增加高职院校学生管 理难度, 难题实现有效管理目标。

三是, 生源多样化背景下高职学生管理存在认知不明确 问题。现阶段, 高职院校缺少学生管理工作的认识, 不能准确 了解到学生管理工作对高职院校自身发展的影响, 使得所采 用的管理方式、教育方式等都存在一定问题, 对高职院校长 远发展产生极其不利的影响。通常情况下, 高职院校学生管 理存在的认知不明确问题所造成的负面影响有以下两点: 一 方面, 由于高职院校学生管理工作存在认知不明确问题, 使 得管理工作中无法考虑到学生适应能力、学校改革方向, 进 而出现盲目管理, 制约高职院校发展。另一方面, 由于高职院 校学生管理工作存在认知问题, 使得的学生管理工作者的工 作心态不端正, 更是缺少专业能力和管理经验, 从而无法实 现高职院校学生管理工作的初衷。

利地投入到了高中阶段的其他学习之中。

\section{[参考文献]}

[1]王金战.高中数学是怎样学好的方法集锦 [M]. 北京: 外语教学与研究出版社,2015:15-20.

[2] 蒋世信.高中数学教学与解题艺术 [M]. 北京: 中国林业 出版社,2006:13-24.

[3]王劲. 高中数学解题教学艺术 [J]. 新课程( 综合 版),2014,(02):85. 在培养同学创造性思维能力的同时, 也让同学更有效、更顺 